\title{
Our cumulative experience with transendoscopic miniprobes
}

\author{
M. J. Varas, R. Abad, J. Turró and J. C. Espinós \\ Unit of Ecoendoscopy. Centro Médico Teknon. Centro Internacional de Medicina Avanzada (CIMA). Barcelona, Spain
}

\begin{abstract}
Introduction: transendoscopic miniprobes (TEMPs) have nowadays precise indications, but may become a diagnostic alternative to both radial and sectorial endoscopic ultrasonography (EUS) in the near future.

Patients and methods: from November 1996 to July 2004 we carried out 620 examinations using TEMPs (124 during the last 12 months in 2003, with currently a mean of 11 examinations/month). Twenty explorations were performed with radial, $12.5 \mathrm{MHz}$ (20 mm penetration), 6.2 F (2 mm diameter), $950 \mathrm{~mm}$ or $2000 \mathrm{~mm}$ Microvasive Endosound probes. Twenty explorations were performed using a $12 \mathrm{MHz}$ (29 mm mean penetration) or $20 \mathrm{MHz}$ (18 mm penetration) Olympus UM-2R/3R, or with a $12 \mathrm{MHz}$ UM-DP12-25R or $20 \mathrm{MHz}$ UM-DP20-25 R DPRfitted Olympus probe, $2.5 \mathrm{~mm}$ in diameter and $2050 \mathrm{~mm}$ in length. A $20 \mathrm{MHz}, 2.2 \mathrm{~mm}$, wire-guided G20-29R was used for intraductal studies.

In all, 580 examinations were carried out with both radial and linear, $12 \mathrm{MHz}(240 \mathrm{E})$ or $20 \mathrm{MHz}$ (60 E) Fuji probes, $2.6 \mathrm{~mm}$ in diameter and $1900 \mathrm{~mm}$ in length; and with a $7.5 \mathrm{MHz}, 2.6 \mathrm{~mm}$ radial balloon microprobe with the well-known "preload" system that we have been using during the 1999-2004 period (280 E). Here we used a $3.2 \mathrm{~mm}$ working channel, whereas a $2.8 \mathrm{~mm}$ working channel was used with the remaining TEMPs.

Results: twenty GI-tract examinations were performed with one Microvasive probe, which broke down when attempting its passage through the papilla.

Currently we use a $20 \mathrm{MHz}, 2.2 \mathrm{~mm}$ Olympus G20-29R guided microprobe for intraductal studies.

We performed 100 gut examinations using one single Fuji TEMP (12 or $7.5 \mathrm{MHz})$.

Organs explored included: esophagus and stomach, 60\%; rectum and colon, 30\%; other (duodenum, papilla, bile ducts), $10 \%$.

Indications: cancer staging, 35\%; submucosal lesions, 30\%; other, 35\% (including 20\% of esophageal non-tumoral conditions).
\end{abstract}

Recibido: 06-09-04.

Aceptado: 04-01-05.

Correspondencia: M. J. Varas-Lorenzo. C. M. Teknon y CIMA. C/ Marquesa de Vilallonga, 12.08017 Barcelona. e-mail: varas@dr.teknon.es. modesto.varas@cimaclinic.com
Complications: aspiration, perforation, and mortality, $0 \%$. Morbidity, $10 \%$, at the expense of abdominal pain as induced by endoscopy itself.

All strictures were successfully passed, except for one malignant stenosis in the rectum.

Conclusions: during a 93-month period (1996-2004) we performed 620 explorations with TEMPs, with a current average of 11 examinations/month. TEMP durability is around 100 gut explorations. The esophagus and stomach were examined in 60\% of cases. Primary indications included gut cancer staging and submucosal lesions (65\%). Perforation and mortality rates amounted to $0 \%$.

Key words: Transendoscopic ultrasound or sonographic miniprobes. High-frequency miniprobes. Miniprobe ultrasonography. Intraductal or endoluminal echography or ultrasonography.

Varas MJ, Abad R, Turró J, Espinós JC. Our cumulative experience with transendoscopic miniprobes. Rev Esp Enferm Dig 2005; 97: 427-431.

\section{INTRODUCTION}

Transendoscopic miniprobes (TEMPs) have nowadays precise indications (1), including the study of biliopancreatic and gastrointestinal tract stenoses (2), colon cancer staging, and the assessment of non-tumor esophageal conditions and submucosal lesions below $2 \mathrm{~cm}$ in size; they also may even become an alternative to both radial and sectorial endoscopic ultrasonography (EUS) in the diagnostic setting (3), since TEMP indications are increasingly more numerous and technical refinement is higher.

In the therapeutic field TEMPs may be of help for echoendoscopy-guided mucosectomy and tumorectomy.

The goal of this publication is to report on a retrospective, descriptive study of our experience with TEMPs. 


\section{PATIENTS AND METHODS}

From November 1996 to July 2004 (more than 7 years, namely 93 months) we performed 620 examinations with TEMPs (124 in the last 12 months during 2003, with currently 11 explorations/month on average during 2004).

Twenty explorations were performed with radial, 12.5 $\mathrm{MHz}$ (20 mm penetration), 6.2 F (2 mm diameter), 950 $\mathrm{mm}$ or $2000 \mathrm{~mm}$ Microvasive Endosound probes.

Twenty explorations were performed using a $12 \mathrm{MHz}$ (29 $\mathrm{mm}$ mean penetration) or $20 \mathrm{MHz}(18 \mathrm{~mm}$ penetration) Olympus UM-2R/3R, or with a $12 \mathrm{MHz}$ UM-DP1225R or $20 \mathrm{MHz}$ UM-DP20-25R DPR-fitted Olympus probe, $2.5 \mathrm{~mm}$ in diameter and $2050 \mathrm{~mm}$ in length. A 20 $\mathrm{MHz}, 2.2 \mathrm{~mm}$, wire-guided G20-29R was used for intraductal studies.

In all, 580 examinations were carried out with both radial and linear, $12 \mathrm{MHz}$ (240 explorations) or $20 \mathrm{MHz}$ (60 explorations) Fuji probes, $2.6 \mathrm{~mm}$ in diameter and $1900 \mathrm{~mm}$ in length; and with a $7.5 \mathrm{MHz}, 2.6 \mathrm{~mm}$ radial balloon microprobe with the well-known "preload" system that we have been using from February 1999 to June 2004 (280 explorations).

Here we used a $3.2 \mathrm{~mm}$ working channel, whereas a 2.8 $\mathrm{mm}$ working channel was used with the remaining TEMPs.

Whenever possible TEMPs were used using the waterimmersion method, and otherwise the direct contact method. No latex miniballon was used, except with the 7.5 MHz microprobe

All explorations were performed following the obtention of the patient's informed consent.

In 1996 the percentage of sedations was 10\%, which has become greater than $90 \%$ in 2004 because of patient requests in our private center.

See a number of reviews for more technical details on TEMPs (3-6).

The following information was obtained: number of explorations performed, duration of TEMP examination, indication and organ to be explored, complications, morbidity and mortality.

Data were processed using the SPSS vs. 11 software package.

\section{RESULTS}

In all, 620 examinations were carried out during the specified period of time.

Twenty GI-tract examinations were performed with one Microvasive probe, which broke down when attempting its passage through the papilla.

Currently we use a $20 \mathrm{MHz}, 2.2 \mathrm{~mm}$ Olympus G2029R guided microprobe for intraductal studies.

We performed 100 gut examinations using one single Fuji TEMP (12 or $7.5 \mathrm{MHz})$.

Organs explored included: the esophagus and stomach in $60 \%(372 / 620)$ of cases; the rectum and colon in $30 \%$
(186/620) of cases; and other (duodenum, papilla, bile ducts) in $10 \%(62 / 620)$ of patients.

Indications: cancer staging in 35\% (217/620) of cases; submucosal lesions in 30\% (186/620) of cases; and other in $35 \%(217 / 620)$ of patients, including $20 \%$ of esophageal non-tumoral conditions.

Impact: there was a change in the diagnostic and therapeutic management of 44 cases among our 100 first patients studied (7). In such cases demographic data, indications, anatomic region to be explored, and changed diagnostic and therapeutic approach - which occurred following the TEMP study- were all recorded.

In the study of gastrointestinal tract strictures, all stenosis were ultimately passed except for one anorectal malignant stricture.

Complications: aspiration, perforation, and mortality, $0 \%$. Morbidity, $10 \%$, at the expense of abdominal pain as induced by endoscopy itself, particularly when sedation was not used.

\section{DISCUSSION}

Studies performed on TEMP durability are few; in relation to intraductal conditions, Napoléon's team (8) limits the use of each individual TEMP to 30 examinations.

Our experience of the gastrointestinal tract using endoluminal TEMP examinations amounts to 100 explorations with one same individual Fuji TEMP.

Nesje et al. (9) studied 123 patients and found additional information for $70 \%$ of cases, whereas Waxman (10) studied 23 patients and found additional information in $74 \%$ and changed patient management in 57\%. The organ most commonly investigated was the esophagus, and major indications included submucosal or mucosal tumors, and esophageal stenoses.

Chak et al. (11) studied 66 patients and performed a comparative investigation of EUS and TEMPs with similar results -18 versus $16 \%$ regarding diagnostic changes, and 21 versus $15 \%$ (31\% in total) regarding therapeutic changes. Organs most commonly explored were the esophagus and stomach, and major indications included mucosal and submucosal tumors, and stenoses (15 cases).

These results are similar to those obtained by our group with a clinical impact of $44 \%$, with the esophagus and stomach being the most commonly explored organs, and staging and submucosal lesions being the main indications seen.

Hünerbein et al. (12) performed locoregional TN staging for 173 patients with esophageal-gastric cancer (63 esophageal, 110 gastric), and concluded that results are similar whether with a $12.5 \mathrm{MHz}$ TEMP or $7.5 \mathrm{MHz}$ linear EUS, with an excellent clinical impact with both procedures.

There is thus scientific evidence that TEMPs may induce changes in the management and therapy of patients with gut and/or malignant conditions in over $30 \%$ of cases. 
Our experience with intraductal TEMPs is insufficient; we have used them in the staging of ampullary tumors and for the study of residual lithiasis.

It offers very positive results in the assessment of pancreatobiliary tumors $(13,14)$, including the precise diagnosis of tumoral extension using 3-D or DPR (14).

The major benefits of TEMPs include fast examinations, the ability to go through strictures and to enter the common bile and pancreatic ducts, better maneuvrability in areas such as the cardia and pylorus, and their potential being of help in mucosectomies and tumorectomies.

Disadvantages or shortcomings include a need for longer training versus EUS, its shorter penetration $(3 \mathrm{~cm}$ at most, whereas EUS reaches $6 \mathrm{~cm}$ on average) and greater fragility, and its inability to support FNAP and interventionist procedures (neurolysis, puncture-injection, etc.). Major indications of EUS and TEMPs include digestive cancer staging and the assessment of submucosal lesions.

To conclude, for 93 months (November 1996 July 2004) we carried out 620 examinations with TEMPs, with currently 11 explorations/month on average.

TEMP durability is approximately 100 gastrointestinal tract examinations. The esophagus and stomach were explored in $60 \%$ of patients. Major indications included gut cancer staging and the study of submucosal lesions $(65 \%)$. Clinical impact had amounted to $44 \%$ in a previous study.

Perforation and mortality rates amounted to $0 \%$, and morbidity was $10 \%$ at the expense of abdominal pain as induced by the endoscopic procedure itself.

\section{REFERENCES}

1. Chak A. How far have come with ultrasound miniprobes? Endoscopy 1999; 31: 329-32.

2. Varas MJ, Abad R, Espinós JC, Turró J. Minisondas ecográficas y estenosis del tracto digestivo. Rev Esp Enferm Dig 2000; 92: 518- 21.

3. Abad R, Varas MJ. ¿Las minisondas ecográficas transendoscópicas son una alternativa a la USE? Rev Esp Ecogr Dig 2004; 6: 46- 51.

4. Menzel J, Domschke W. Gastrointestinal miniprobe sonography: The current status. Am J Gastroenterol 2000; 95: 605-16.

5. Boustière Ch. Ultrasonographie par mini-sondes perendoscopiques: principes d'utilisation. Acta Endoscopica 2001; 31: 27-9.

6. Varas MJ. Minisondas ultrasonográficas transendoscópicas, ¿son necesarias? Rev Esp Enferm Dig 2003; 95: 49-54.

7. Varas MJ, Abad R, Turró J, Espinós JC. Ultrasonografía transendoscópica mediante minisondas (MS). Resultados preliminares. Rev Esp Ecogr Dig 2000; 2 : 188-91.

8. Napoléon B. Les minisondes d'endosonographie: indicacions bilio-pancréatiques. Acta Endoscopica 2000; 30: 367-70.

9. Nesje LB, Odegaard S, Kimmey MB. Transendoscopic ultrasono-graphy during conventional upper gastrointestinal endoscopy. Clinical evaluation of a linear $20 \mathrm{MHz}$ probe system. Scand J Gastroenterol 1997; 32: 500-8.

10. Waxman I. Clinical impact of high-frequency ultrasound probe sonography during diagnostic endoscopy- A prospective study. Endoscopy 1998; 30 (Supl. 1): A166-A168.

11. Chak A, Soweid A, Hoffman B. Clinical implications of endoluminal ultrasono-graphy using through-thescope catheters probes. Gastrointest Endosc 1998; 48: 485-90.

12. Hünerbein M, Ulmer C, Handke T, Schlag PM. Endosonography of upper Gastrointestinal tract cancer on demand using miniprobe

13. or endoscopic ultrasound. Surg Endosc 2003; 17: 6159.

14. Tamada $\mathrm{K}$, Inui $\mathrm{K}$, Menzel $\mathrm{J}$. Intraductal ultrasonography of the bile duct system. Endoscopy 2001; 33: 878-85.

15. Inui $\mathrm{K}$, Yoshino J, Okushima $\mathrm{K}$, Miyoshi $\mathrm{H}$, Nakamura Y. Intraductal EUS. Gastrointest Endosc 2002; 56 (Supl.): S58-S62. 